\title{
Serviço Social e inserção social da Pós-graduação: reflexões a partir do oeste do Paraná
}

\section{Social Work and social insert of Post-graduate: reflexions from west of Paraná}

\section{Diuslene Rodrigues da Silva ${ }^{a}$ \\ (1) https://orcid.org/0000-0002-1753-5509}

Esther Luiza de Souza Lemos ${ }^{a}$

(1) https://orcid.org/0000-0002-7154-1475

Alfredo Batista ${ }^{a}$

(D) https://orcid.org/0000-0003-1029-9598

Resumo: 0 artigo objetiva evidenciar a concepção e ações desenvolvidas no campo da inserção social a partir da realidade sócio-histórica da pós-graduação em Serviço Social na Universidade Estadual do Oeste do Paraná - Unioeste, localizada na tríplice fronteira internacional no Sul do país. Reflete sobre o sentido ético-político do Serviço Social como área de conhecimento e da inserção social incluída como quesito no modelo de avaliação da Capes.

Palavras-chave: Serviço Social. Inserção social. Pós-graduação. Unioeste.
Abstract: The goal of the paper is to highlight the conception and actions developed in social insert field having as starting point the historical and social reality of Social Work Post Graduation course at Western State University of Paraná - UNIOESTE, located in the triple internacional border in the south of the country. It reflects upon the political and ethical meaning of Social Work as a field of knowledge and the social insert included as requirement in Capes evaluation model.

Keywords: Social Work. Social insert. Post-graduate. Unioeste. 


\section{Introdução}

onsiderada uma inovação no modelo de avaliação da Coordenação de Aperfeiçoamento de Pessoal de Nível Superior - Capes, o quesito inserção social como categoria de avaliação foi introduzido no contexto do IV Plano Nacional de Pós-Graduação - PNPG (2005-10), no segundo mandato do governo Lula da Silva. Tendo à frente da Divisão de Avaliação da Capes Renato Janine Ribeiro (USP), a quem coube coordenar a implantação do mesmo, a partir da Avaliação Trienal 2007, o quesito inserção social passou a ter um peso fixo de $10 \%$ na avaliação dos mestrados e dos doutorados acadêmicos. ${ }^{1} \mathrm{Na}$ concepção da agência, a inserção social "Não se trata de mera aplicação de um conhecimento pronto a realidades que clamam por ele. Para a pós, é importante que esses trabalhos retroalimentem a pesquisa e a formação" (Ribeiro, 2012, p. 84).

A partir de então, o quesito inserção social se manteve na ficha de avaliação para todos os programas de pós-graduação no país. Tal quesito impõe-se a partir da constatação e crítica referente ao hiato ou abismo existente entre universidade e sociedade. O VI Plano Nacional de Pós-Graduação (2011-2020), ao abordar o sistema de avaliação, considera que o "taylorismo intelectual e o imperativo do publish ou perish invadiram todas as áreas e isso refletiu na avaliação, com o predomínio da quantidade sobre a qualidade" (Brasil, 2010, p. 127).

Os paradoxos e dilemas experimentados pelas universidades brasileiras e programas de pós-graduação também são vivenciados na área de Serviço Social. É nesse contexto que historicamente a área tem feito o enfrentamento ao produtivismo acadêmico e à competitividade geradas contraditoriamente pelo próprio modelo de avaliação da Capes.

Neste texto, como assistentes sociais com exercício profissional no ensino superior, temos o objetivo de evidenciar a concepção e as ações

Para distribuição do referido quesito foram definidas quatro dimensões de impacto: tecnológico/econômico, educacional, cultural e impacto propriamente social. A partir daí, cada área de conhecimento possui autonomia para definir como entende a inserção social. 
desenvolvidas no campo da inserção social a partir da realidade sócio-histórica na qual a Universidade Estadual do Oeste do Paraná - Unioeste, campus de Toledo, está inserida e na qual realizamos o trabalho docente na graduação e pós-graduação em Serviço Social.

Tendo como base a pesquisa bibliográfica e documental sobre o tema, o acúmulo da luta sindical na universidade juntamente com a experiência acadêmico-organizativa no conjunto da categoria, reafirmamos o sentido ético-político da produção do conhecimento comprometido com os interesses da classe trabalhadora.

Neste sentido, a defesa da universidade pública, gratuita, laica, de qualidade e socialmente referenciada é condição imperativa na atual conjuntura de contrarreformas na educação, previdenciária, trabalhista, administrativa etc. É imperativa a defesa da ciência e a reafirmação do compromisso ético-político do Serviço Social brasileiro contra a regressão de direitos, o negacionismo e a mercantilização de todas as dimensões da vida social.

\section{Universidade e desenvolvimento regional: a particularidade sócio-histórica da Unioeste}

Historicamente, o conhecimento científico teve lugar estratégico no projeto burguês, fazendo parte da disputa dos "cérebros" e da inteligência nacional. Porém o atual contexto político-econômico do país evidencia uma aguda contradição.

O núcleo econômico do governo Bolsonaro, ultraneoliberal, é constituído pelos representantes dos bancos e das organizações financeiras, em tese, setores modernos e internacionalizados, ao lado do agronegócio exportador e de atacadistas, igualmente com pretensão cosmopolita. Individualmente, nenhum de seus agentes se apresentaria ao mundo como agentes do irracionalismo e negacionistas de todas as grandes evidências científicas que marcam o tempo atual [...]. (Leher, 2019, p. 12) 
Os desmontes da educação, da ciência e da cultura, implementados pelo atual governo juntamente com o fundamentalismo religioso e a ação de grupos de extrema-direita na cruzada contra o chamado "marxismo cultural" e "doutrinação" no interior da universidade, expressam "a recalibração das expropriações e do padrão de exploração subjacentes ao capitalismo dependente - em nova fase, ainda mais destrutiva [...]" (Leher, 2019, p. 13). É uma estratégia de como elevar a taxa de lucro dos capitalistas no país eliminando focos de resistência. Neste sentido, a educação, a ciência e a cultura são setores estratégicos e em disputa.

Para Araújo (2013), a expansão da universidade pública foi uma das principais políticas setoriais, posta num processo contraditório de “desenvolvimento urbano-regional”, ainda que seja difícil identificá-la como sendo uma política relacionada a grandes projetos de integração e desenvolvimento regional.

Ao longo da história, no cotidiano da paisagem rural paranaense, passaram a coexistir processos produtivos globais de exploração e de conflitos sociais, como a organização de trabalhadores sem-terra, agricultores familiares, assentamentos rurais e agrovilas, simultâneos à ampliação das atividades econômicas e de trabalho rural não agrícola. As estruturas geradas pela dita produção moderna produziram significativas transformações no comportamento demográfico (Moro, 2000).

Nos anos 1980, as mudanças de territorialidade impulsionadas pelas novas atividades econômicas foram concluídas no estado do Paraná, resultando nas instalações dos complexos agroindustriais e no agronegócio. Na região oeste, conhecida pelos seus frigoríficos de aves e suínos, também destaca-se a indústria de transformação de alimentos, a produção de leite e tilápia para o mercado nacional. Na produção agrícola paranaense, a região lidera o cultivo de milho e soja (Mazuchetti, 2007).

Também concentra o terceiro maior destino de turistas estrangeiros no país, as Cataratas do Iguaçu na cidade de Foz do Iguaçu, primeiro destino na região Sul, marcando a fronteira com a Argentina. Ao mesmo tempo, a região alterou-se com a construção da Usina Hidrelétrica de 
Itaipu, entre 1975 e 1982, usina binacional construída no rio Paraná, fronteira entre Brasil e Paraguai, durante a ditadura civil-militar dos dois países. Se por um lado a Itaipu Binacional continua sendo líder mundial em produção de energia limpa e renovável, sendo fator de desenvolvimento e acumulação de riqueza, a inundação do lago de Itaipu desalojou milhares de famílias de agricultores brasileiros e paraguaios. Simultaneamente, após o término da construção da barragem, inúmeros trabalhadores ficaram desempregados, migrando ou permanecendo na região, intensificando-se nesse período o comércio ilegal na fronteira com o Paraguai.

A atual configuração econômica e demográfica das cidades de médio porte não se deu ao acaso; elas refletem produtos de intervenções governamentais que inicialmente buscaram promover a distribuição das atividades, das riquezas da população sobre o espaço nacional e territorial focada no modelo de planejamento de promoção de equilíbrio urbano-regional. Assim, redirecionou fluxos migratórios, fluxos de capital e a viabilidade de sistemas de produção, mas que, ao final, socializou também as desigualdades socioeconômicas que emanam desse modelo.

Numa lógica dialética, a implantação da universidade pública em territórios onde se desenvolvem cidades de médio e pequeno porte não atende somente aos interesses de demanda econômica, ou a única necessidade de qualificação do trabalho que se destina ao atendimento do setor produtivo instalado. A universidade pública interiorizada visa também formar profissionais que atendam os serviços ligados às demandas da educação, da saúde, da assistência social e da previdência social, dentre outras, incentivando e possibilitando a implantação de pesquisas para diversas necessidades regionais (Araújo, 2013).

O processo de implantação da universidade pública estadual nas regiões oeste e sudoeste do Paraná foi de intensa mobilização das diferentes forças políticas, marcando meados da década de 1970 e início da de 1980. Antes de existir a universidade formalmente reconhecida, foram 
criadas fundações municipais de ensino superior, instituições de direito público municipal com oferta de cursos pagos nas cidades de Cascavel, Toledo, Foz do Iguaçu, Marechal Cândido Rondon e Francisco Beltrão.

Inicialmente, a mobilização regional deu-se na luta pela federalização, sendo inviabilizada naquele momento. Com a negativa do governo federal, a mobilização centrou-se na estadualização com gratuidade do acesso, sendo um processo longo e de intensas negociações com o governo estadual. Nesse período, o Sistema Estadual de Ensino Superior contava com três universidades: Universidade Estadual de Maringá - UEM, Universidade Estadual de Ponta Grossa - UEPG, ambas criadas em 1969, e a Universidade Estadual de Londrina - UEL, criada em 1970. De caráter multicampi, a partir dos cursos ofertados nas cidades da região, a Unioeste foi criada em 1987.

O curso de Serviço Social no campus de Toledo foi o primeiro de graduação a ser criado nas regiões oeste e sudoeste do Paraná, em 1987, havendo naquele momento cinco cursos no estado. Desde sua gênese, o curso de Serviço Social tem se caracterizado no contexto universitário e regional pela sua inserção social, efetivada por ações de docentes e discentes, especialmente por meio de projetos de extensão. No ano 2000 foi implantado o novo projeto político-pedagógico, tendo como base a proposta de Diretrizes Curriculares aprovada em 1996 na assembleia da então Associação Brasileira de Ensino em Serviço Social - Abess.

Funcionando respectivamente nos municípios de Cascavel, Foz do Iguaçu, Francisco Beltrão, Marechal Cândido Rondon e Toledo, a Unioeste abrange um total de 52 municípios na região oeste e 42 municípios na sudoeste, totalizando o alcance a 94 dos 399 municípios do Paraná. A região é de fronteira internacional, marcada pela tríplice fronteira entre Brasil, Argentina e Paraguai. Apreender essa região em sua particularidade de área transfronteiriça tem sido um desafio para a universidade que se coloca em movimento nas suas finalidades de ensino, pesquisa e extensão. 


\section{A pós-graduação em Serviço Social e as ações de inserção social}

No processo de expansão do Sistema Nacional de Pós-Graduação e da Unioeste, em 2013 foi criado o mestrado em Serviço Social, com natureza acadêmica, numa conjuntura econômica regressiva e de ataques frontais à autonomia universitária, ao seu financiamento público e à liberdade de expressão.

Depois de longo e continuado investimento público no processo de qualificação do corpo docente em nível de doutorado e diminuição da rotatividade de professores(as) na área, iniciaram-se as atividades do mestrado. Nos seus 33 anos de existência, a graduação em Serviço Social formou 803 assistentes sociais. Estes, atuando nos mais diferentes espaços sócio-ocupacionais, nas diferentes políticas sociais, representam a maior demanda pelo mestrado. Além deles, existe demanda de profissionais formadas(os) em cursos de graduação privados presenciais, fruto da expansão dessa oferta na região. Profissionais de áreas afins, como Psicologia, Direito, Filosofia e Relações Internacionais, também têm demandado o curso de mestrado.

Atualmente, o corpo docente é composto por doze docentes permanentes e um colaborador, implementando a proposição da área de concentração Serviço Social, Política Social e Trabalho Profissional, com duas linhas de pesquisa: "Fundamentos do Serviço Social e do trabalho profissional" e "Política social - fundamentos, gestão e análise".

Em 2019, o curso totalizou cinco turmas egressas, titulando 44 mestres em Serviço Social. Nesse mesmo ano foi realizado o I Encontro de Egressas(os) do PPGSS, contando com a participação externa do dr. Maurílio Matos (Uerj) tematizando sobre "os rumos da pesquisa no Serviço Social brasileiro”. Durante o encontro, foi apresentado o perfil das(os) egressas(os) do programa e construídas estratégias para o fortalecimento desse vínculo institucional.

Como exposto anteriormente, o curso de Serviço Social na Unioeste é conhecido por sua forte inserção nas atividades extensionistas na 
região. Historicamente, o corpo docente coordenou e desenvolveu ações com abrangência regional, fortalecendo sua legitimidade e a articulação entre a universidade e a sociedade. Um dos aspectos dificultadores tem sido a falta de financiamento público, tanto em atividades de pesquisa, extensão, quanto na organização de eventos.

O programa, por intermédio de seu corpo docente e discente, tem investido nas atividades de inserção social na perspectiva da necessária articulação entre graduação e pós-graduação e entre as atividades fins da universidade: ensino, pesquisa e extensão. Tem sido atuante na representação da área nos espaços públicos de participação e organização da sociedade civil, caracterizando sua inserção no conhecimento aprofundado da realidade social com compromisso com a defesa de direitos sociais. Ao mesmo tempo, como pesquisadores na área, o corpo docente tem participado de eventos nacionais e internacionais, participado como pareceristas, avaliadoras(es) ad hoc, editores e membros de corpo editorial de periódicos nacionais, organizadoras(es) de eventos científicos nacionais, ampliando a interação, a solidariedade e a experiência profissional.

Como ações de inserção social do PPGSS na realidade regional destacamos:

- A participação ativa nos espaços públicos de controle social como os conselhos gestores e de direitos no município de Toledo, sendo eles: Conselho Municipal de Assistência Social, Conselho Municipal dos Direitos da Criança e do Adolescente, Conselho Municipal sobre Drogas.

- A trajetória dos projetos de extensão na política de educação permanente tanto para conselheiros municipais quanto para trabalhadores(as) do Sistema Único de Assistência Social - Suas, bem como trabalhadoras(es) vinculadas(os) à política de atenção à criança e ao adolescente e conselheiras(os) tutelares tem sido um marco histórico na inserção social nas regiões oeste e sudoeste do Paraná, obtendo financiamento das respectivas secretarias de Estado bem como do governo federal por meio do Programa CapacitaSuas, 
compondo a Rede Nacional de Capacitação e Educação Permanente do Suas - Renep/Suas.

- $\quad \mathrm{Na}$ atenção à criança e ao adolescente, destacamos a importante inserção local com articulação internacional no enfrentamento à violência, abuso e exploração sexual contra crianças e adolescentes e na implantação do serviço da Rede Intersetorial de Proteção Social de Toledo - Rips.

- Sendo uma região fortemente marcada pelas demandas do movimento indígena, o projeto de extensão “Ações socioambientais em defesa dos direitos dos povos indígenas: comunidade indígena de Tekoha Yhovy e Escola Mbyja Porã - localizadas no Município de Guaíra - PR", tem sido uma experiência marcante, envolvendo também o Programa de Educação Tutorial — PET - Meio ambiente com doze estudantes bolsistas da graduação em Serviço Social.

- No contexto da campanha nacional "Assistentes sociais no combate ao racismo", promovido pelo conjunto CFESS/Cress, docentes do PPGSS propuseram um projeto de extensão sobre a temática. $\mathrm{O}$ projeto "Cores da resistência" envolve docentes da área de Serviço Social e Educação, profissionais dos serviços no âmbito das políticas sociais nas regiões oeste e sudoeste, além de estudantes da graduação da área de Serviço Social, Ciências Sociais e Filosofia.

- $\quad$ apoio institucional à participação docente na representação da categoria dos(as) assistentes sociais, via mandato eletivo através de eleições livres e diretas, por meio de suas entidades, tem marcado o PPGSS. Por intermédio de seu corpo docente, participou da gestão do Conselho Federal de Serviço Social — CFESS nas gestões 2011-14 e 2014-17. Docentes do PPGSS têm assumido o protagonismo na organização da categoria na região, particularmente no processo de criação da Seccional do Conselho Regional de Serviço Social - Cress $11^{\text {a }}$ Região em Cascavel em 2018. A participação ativa dos docentes do curso tem fortalecido a organização coletiva e a aproximação com as demandas profissionais na região. No âmbito da formação profissional, a inserção construída ao longo do processo de participação 
coletiva na Abepss culminou com a eleição da representação de docentes do PPGSS da Unioeste na gestão da entidade para o biênio 2019-20.

A concepção de inserção social que orienta o projeto pedagógico do mestrado em Serviço Social na Unioeste tem como referência o princípio ético do compromisso com a qualidade dos serviços prestados à população e com o aprimoramento intelectual. Neste sentido, ao longo desses sete anos de existência, a formação profissional dos recursos humanos vinculados ao curso, estudantes regulares e egressos, tem sido de trocas permanentes com a realidade regional.

A influência teórica e acadêmica do programa está enraizada na particularidade transfronteiriça, dialogando com as duas linhas de pesquisa que o orientam. Neste sentido, a inserção social alimenta a produção intelectual de docentes e discentes, mantendo relação visceral com o mercado de trabalho.

A incidência das ações realizadas, além do conhecimento dos diferentes espaços sócio-ocupacionais e necessidades de usuários, contribuiu na qualificação dos instrumentais técnico-operativos, incidindo diretamente nos serviços prestados à população. A articulação ensino, pesquisa e extensão, particularmente na pós-graduação, é central para o fortalecimento da inserção social comprometida com a transformação qualitativa da realidade brasileira. Para além da obtenção da titulação, a formação comprometida com a inserção social permite ampliar o campo de reflexão e da intervenção cotidiana, adensando o compromisso ético da ciência no país.

\section{Considerações finais}

Considerando a particularidade do programa no âmbito regional e a crítica ao fenômeno descrito por Florestan Fernandes de "farisaísmo intelectual sistemático, tão tosco e provinciano quão arrogante e 
antissocial" (2004, p. 297), entendemos que foi absolutamente relevante a inclusão, a partir de 2007, do quesito inserção social no modelo de avaliação da Capes.

A inserção social efetivada na área de Serviço Social tem a possibilidade de relação intrínseca com o sentido ético-político do projeto profissional que, há quarenta anos, tem orientado o Serviço Social brasileiro. Reconhecemos que, como área de produção do conhecimento, o Serviço social possui "um quadro docente com a competência exigida para uma formação compatível com as demandas da sociedade brasileira” (Garcia e Nogueira, 2017, 152).

Iamamoto (2007, p. 468), ao analisar a pós-graduação em Serviço Social e os rumos da pesquisa, afirma que

Esse momento exige dos pesquisadores uma atividade intelectual aberta a compreender o novo, presidida por elevados valores éticos e guiada por normas de responsabilidade intelectual, atribuindo à pesquisa uma ampla dimensão pública que adense uma vigília crítica do Brasil, de modo que se possa afirmar, com o poeta Murilo Mendes, "não sou meu sobrevivente e sim meu contemporâneo".

Essa convocatória foi realizada há mais de uma década e permanece absolutamente relevante e desafiadora! Em tempos de obscurantismo e miséria da razão, é imprescindível investirmos no trabalho intelectual, na ciência e na produção do conhecimento em vigília crítica do Brasil.

\section{Referências}

ARAÚJO, Tânia Bacelar. Desenvolvimento regional brasileiro e políticas públicas federais no governo Lula. In: SADER. Emir (Org.). 10 Anos de governos pós-neoliberais no Brasil. Rio de Janeiro: Boitempo, 2013.

BRASIL. Ministério da Educação. Coordenação de Aperfeiçoamento de Pessoal de Nível Superior. Plano Nacional de Pós-Graduação - PNPG 2011-2020. Brasília: Capes, 2010. Disponível em: https://www.capes.gov.br/images/stories/download/Livros-PNPG-VolumeI-Mont.pdf. Acesso em: 20 jan. 2020. 
FERNANDES, Florestan. Universidade e desenvolvimento. In: IANNI, Octavio (Org.). Florestan Fernandes: sociologia crítica e militante. São Paulo: Expressão Popular, 2004.

GARCIA, Maria Lúcia Teixeira; NOGUEIRA, Vera Maria Ribeiro. Reflexões sobre a pós-graduação em Serviço Social no Brasil através do perfil dos docentes. Revista Katálysis, Florianópolis, v. 20, n. 2, p. 145-154, maio/ago. 2017. Disponível em: http://www.scielo. br/pdf/rk/v20n2/pt_1414-4980-rk-20-02-00155.pdf. Acesso em: 15 jan. 2020.

IAMAMOTO, Marilda Villela. Serviço Social em tempo de capital fetiche: capital financeiro, trabalho e questão social. São Paulo: Cortez, 2007.

LEHER, Roberto. Autoritarismo contra a universidade: o desafio de popularizar a defesa da educação pública. São Paulo: Expressão Popular, 2019.

MAZUCHETTI, Roselis Natalina. O programa seis sigma em uma indústria de abate de aves. Toledo: Unioeste, 2007. 123 p.

MORO, Dalton Áureo. Transformações sócio-espaciais decorrentes da modernização da agricultura no Estado Paraná. In: $1^{\circ}$ ENCONTRO NACIONAL DE GEOGRAFIA AGRÁRIA. Anais: comunicações. Goiânia: Universidade Federal de Goiás, Instituto de Estudos Socioambientais, 2000. p. 352-355.

RIBEIRO, Renato Janine. Para que serve a avaliação da pós-graduação. a visão da Capes. Revista Argentina de Educación Superior - RAES, Buenos Aires, ano 4, n. 5, out. 2012. Disponível em: http://www.revistaraes.net/revistas/raes5_art3.pdf. Acesso em: 20 jan. 2020.

\section{Sobre o(as) autor(as)}

Diuslene Rodrigues da Silva - Doutora em Desenvolvimento Regional e Agronegócio (UNIOESTE), professora da graduação e do Programa de Pós-graduação em Serviço Social.

E-mail: diuslene.fabris@hotmail.com

ESTHER Luíza DE SouZa Lemos - Doutora em Serviço Social (UFRJ), professora da graduação e do Programa de Pós-gradução em Serviço Social.

E-mail: estherlemos@gmail.com

Alfredo Batista - Doutor em Serviço Social (PUC-SP), professor da graduação e do Programa de Pós-graduação de Serviço Social.

E-mail: comuna12@uol.com.br 